\title{
Phase-II Studies of 1,2, 4-Triglycidylurazol (TGU) in Solid
}

\section{Tumors}

Phase-II Study Group of the Association of Medical Oncology of the German Cancer Society

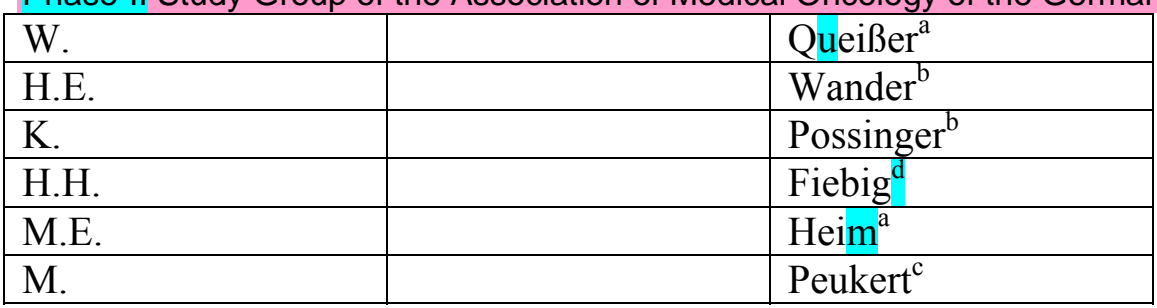

${ }^{a}$ Oncological Center, Clinics of Mannheim ${ }^{b}$ Dept. of Hematology, Oncology, UniversityClinics of Göttingen ${ }^{C}$ Med. Clinic III, Center Grosshadern, Munich ${ }^{d}$ Dept. of Internal Medicine, University-Clinics, Freiburg i.Br. ${ }^{\mathrm{e}}$ Med. Clinics Bielefeld

Request for reprints to: Prof. Dr. W. Queißer, Onkologisches Zen-trum, Klinikum Mannheim, Postfach 23, D-6800 Mannheim 1

The cytostatic activity of bifunctional epoxides, e.g. dianhy-drogalactitol (DAG) or dibromodulcitol,is well known. Therefore it seemed interesting to develop compounds with a higher number of epoxide groups. The first triepoxide subjected to intensive preclinical and clinical screening was alpha-trigly-cidyltriazinetrione (teroxirone, TGT) produced by HenkelCompany, FRG. However, administration of this compound led to strong local reactions (phlebitis). The 1,2, 4-triglycidyl-urazol (TGU), which was also produced by Henkel, showed better physico-chemical properties, especially stability and solubility, and a more favorable therapeutic spectrum in preclinical tests. The path of cytotoxic action is not known. Compared to the bifunctional epoxides as DAG an alkylating effect is accepted. TGU has been shown to be active in a number of experimental murine tumors [1], the hematologic toxicity being dose-limiting. During 1983 three phase-I studies were published [24]. The recommended dosage for phase-II studies was $800 \mathrm{mg} / \mathrm{m} 2$, iv, every four weeks $(650$ $\mathrm{mg} / \mathrm{m} 2$ for pretreated patients) or $200 \mathrm{mg} / \mathrm{m} 2 /$ die $\times 5$ die, iv, every four weeks. On the basis of own guidelines of the phase-II study group [5] five phase-II trials of TGU were initiated for nonsmall cell cancer of the lung, non-Hodgkin lymphoma with low malignancy, colorectal, breast and renal cancer. With the exception

Table I. Patient characteristics, dose schedules, treatment results, and toxicity of four phase-II trials using TGU in solid tumors

\section{Breast}

Lung

Colon/ rectum

Kidney 


\section{Total}

Patients, total

23

14

14

16

67

evaluable

17

14

14

16

61

Male/female

$0 / 23$

$10 / 4$

$7 / 7$

$10 / 6$

27/40

Age, mean

57.0

57.9

56.8

58.6

57.5

range

40-72

41-69

44-73

37-69

37-73

Performance (0-4)

1.95

1.29

0.86

1.19

1.34

Pretreatment chemotherapy

yes

no 
no

no

Dosage of TGU

$600 \mathrm{mg} / \mathrm{m} 2 \mathrm{dl}$

$600-800 \mathrm{mg} / \mathrm{m} 2$

dl

$200 \mathrm{mg} / \mathrm{m} 2 \mathrm{dl}-5$

$600 \mathrm{mg} / \mathrm{m} 2 \mathrm{dl}$

17

14

14

16

1 cycle

13

10

7

15

61

2 cycles

3

5

2

8

45

3 and more cycles

0

0

0

0

18

CR

1

0

1

0

0 
PR

0

3

2

8

$2 / 45$

$\mathrm{NC}$

12

7

4

7

$13 / 45$

$\mathrm{P}$

5

5

4

6

30/45

Nadir WBC 1-2

3

1

1

0

20/61

3-4

1

3

2

1

$5 / 61$

Nadir platelets 1-2

3

1

1

0

$7 / 61$

3-4

22

.7 
Nausea vomiting 1-2

1

1

0

9

Local reactions and thrombophlebitis

Short Communications: Queißer et al.

of the lymphoma trial which was terminated early, a minimum of 14 patients per trial has been treated with TGU so far.

Patients and Methods

A total of 67 patients entered the four protocols. Within lung cancer, 6 had adenocarcinoma, 6 squamous cell carcinoma, 1 large cell and another 1 adeno-squamous carcinoma. Two patients had received previous X-ray treatment. Within the colorectal group, 9 had colon and 6 rectum carcinoma. The clinical characteristics of the patients are summarized in table I. All patients, except those with breast cancer, were not pretreated with chemotherapy. As seen in table I, two different dose schedules were administered.

Results

Of 61 evaluable patients, 45 obtained two treatment cycles and were evaluated for response (table I). Two patients showed a partial remission suggesting an overall response rate of $4.4 \%$. The remissions were observed in a woman with cutaneous and pleural metastases of breast cancer and in a patient with lung metastases of advanced colon cancer.

Toxicity of treatment was considerable (table I). The data evaluated after the first cycle show leukopenia grade 3-4 (WHO) of $8 \%$, grade $1-4$ of $41 \%$, thrombocytopenia grade $3-4$ of $8 \%$ and $1-4$ of $20 \%$. Nausea and vomiting grade $1-4$ were seen in $92 \%$, grade $3-4$ in $18 \%$ of the patients, and local reactions were seen in 18\%. One drug-related death (sep-ticemia) was observed. 


\section{Discussion}

The data presented in the four phase-II trials suggest minimal activity of TGU in the solid tumors studied, accompanied by considerable toxicity. The drug was further studied by the EORTC Early Clinical Trials Group [6]. At the time of presentation, of 202 treated patients with lung cancer, colorectal cancer, malignant melanoma, kidney cancer and pretreated breast cancer 69 were evaluable. Only one partial remission in a patient with breast cancer was observed. Therefore, our results and the data in the literature suggest that TGU in the applied dosages is not thought suitable for treatment of solid tumors in humans.

References

Hilgard, P.; Peukert, M.; Pohl, J.: Alpha/beta-Triglycidyl-urazol (TGU, NSC 332 448,1.N.N.: Anaxirone): A new chemotherapeutic agent. Cancer Treat. Rev. 11: 115-120 (1984). Hansen, S. W.; Bach, F.; Hansen, H. H.: Phase I study of 1, 2, 4-triglycidylurazol (TGU, NSC 332 448). An early clinical trials group study - EORTC. Fourth NCI-EORTC Symposium on New Drugs in Cancer Therapy, Brussels, Dec. 14-17, Abstract 53 (1983).

Rozencweig, M.; Crespeigne, N.; Nicaise, C; Gerard, B.; Atassi, G.; Tagnon, H.; Kenis, Y.: Phase I trial of 1, 2, 4-triglycidyl-urazol (TGU, NSC 332 448) with a daily $\times 5$ schedule. 4th NCI-EORTC Symposium on New Drugs in Cancer Therapy, Brussels, Dec. 14-17, Abstract 132 (1983).

Stuart, J. F. B.; Soukop, M.; Cunningham, D.; Gilchrist, N.; Forrest, G.; Kaye, S. B.; Caiman, K. C: Pharmacokinetics and pharmacology during a phase I trial on triglycidylurazol (TGU). 4th NCI-EORTC Symposium on New Drugs in Cancer Therapy, Brussels, Dec. 14-17, Abstract 130 (1983).

Queißer, W.: Richtlinien der AIO zur Abfassung von Protokollen der Phase-ПI-Prüfung von Zytostatika. Onkologie 8: 133-136 (1985).

Hansen, H. H.; Ten Bokkel Huinink, W. W.; Holdener, E.; Bruntsch, U.; Gunderson, S.; Pinedo, H. M.; Renarid, J.: Phase II studies of alpha/beta-triglycidyl-urazol (TGU, NSC 332448 I.N.N.: Anaxirone): A new chemotherapeutic agent. 3rd Eur. Conf. Clin. Oncol. Stockholm, June 16-20, No. 212 (1985).

Onkologie 9: 285-286 (5/1986) 